\title{
PENGEMBANGAN E-MODUL INTERAKTIF BERBASIS CASE (CAPTURE, SOLVE AND EVALUATION) PADA MATERI LUAS PERMUKAAN DAN VOLUME KUBUS DAN BALOK UNTUK SEKOLAH MENENGAH PERTAMA TAHUN AJARAN $2017 / 2018$
}

\author{
Winda Seruni Wahyu Asih ${ }^{1}$ \\ ${ }^{1}$ Guru Matematika SMP Negeri 1 Kalibaru \\ Email: ${ }^{1}$ windaseruniwahyuasih@gmail.com,
}

\begin{abstract}
Abstrak
Pengembangan ini bertujuan mengetahui hasil pengembangan E-modul Interaktif Berbasis CASE (Capture, Solve, and Evaluation) pada Materi Luas Permukaan dan Volume Kubus dan Balok untuk Sekolah Menengah Pertama Tahun Ajaran 2017-2018, serta melakukan validasi dan uji coba e-modul interaktif matematika. Pada penelitian ini dilakukan dengan metode penelitian pengembangan, yang mengacu pada model pengembangan 4-D yang meliputi 4 tahap, yaitu define, design, develop, dan disseminate. Subjek validasi terdiri dari satu ahli materi, satu ahli desain, satu praktisi, dan 9 siswa kelas VIII sebagai user/pengguna. Untuk teknik analisis data diambil dari data kuantitatif dan kualitatif. Berdasarkan data hasil validasi produk, penilaian validator ahli materi memenuhi kriteria valid dengan skor $85,51 \%$, penilaian validator ahli desain dan media memenuhi kriteria valid dengan skor $84,13 \%$, penilaian validator praktisi memenuhi kriteria sangat valid dengan skor $92,41 \%$, dan penilaian produk oleh user (pengguna) memenuhi kriteria praktis dengan skor $87,83 \%$. Sehingga dapat disimpulkan bahwa emodul interaktif berbasis CASE (Capture, Solve and Evaluation) pada materi luas permukaan dan volume kubus dan balok untuk sekolah menengah pertama tahun ajaran 2017/2018 adalah valid dan layak digunakan.
\end{abstract}

Kata Kunci: e-modul interaktif, CASE ( Capture, Solve and Evaluation), luas permukaan dan volume, kubus dan balok

\section{PENDAHULUAN}

Dunia pendidikan adalah dunia yang sangat penting dalam kehidupan manusia. Manusia yang selalu diiringi pendidikan, kehidupannya akan selalu berkembang ke arah yang lebih baik (Hamid, 2011). Pendidikan juga menjadi pilar utama dalam mewujudkan perubahan manusia ke arah yang positif dan menuju pencapaian potensi kemanusiaan tertinggi.

Namun pada era sekarang banyak fenomena yang sering terjadi pada peserta didik saat ini, dimana mereka menganggap bahwa aktivitas atau kegiatan yang mengasyikkan justru berada di luar jam pelajaran. Hal ini dikarenakan selama ini mereka merasa terbebani ketika berada di dalam kelas, apalagi jika harus menghadapi mata pelajaran tertentu yang membosankan. Melihat fenomena tersebut peran pendidik sangatlah penting dalam proses pembelajaran, sehingga pendidik dituntut untuk membuat proses pembelajaran lebih menyenangkan dan tidak membosankan untuk peserta didik. Menurut Melvin (dalam Hamid, 2011), belajar bukan merupakan konsekuensi otomatis dari penyampaian informasi kepada peserta didik.

Pembelajaran matematika memiliki peranan penting dalam berbagai segi kehidupan. Matematika memberikan kemampuan berfikir logis, analitis, sistematis, kritis, kreatif, dan 
kemampuan bekerja sama (Suherman, 2003:60). Matematika juga merupakan hal yang wajib dipelajari dalam dunia pendidikan, namun pada era sekarang matematika sering dianggap pembelajaran yang membosankan dan tidak asyik oleh para peserta didik. Maka dari itu, kita membutuhkan kreatifitas dan inovasi dalam penyampaian pembelajaran matematika agar dapat disenangi oleh para peserta didik.

Modul dapat diartikan sebagai materi pelajaran yang disusun dan disajikan secara tertulis sedemikian rupa sehingga pembacanya diharapkan dapat menyerap sendiri materi tersebut. Dengan kata lain sebuah modul adalah sebagai bahan belajar dimana pembacanya dapat belajar sendiri (Daryanto, 2013:31). Dengan menerapkan modul pembelajaran, dapat mendorong peserta didik lebih aktif, terampil, dan memiliki pengetahuan yang luas ketika proses pembelajaran. Modul adalah alat atau sarana pembelajaran yang berisi materi, metode, batasan-batasan materi pembelajaran, petunjuk kegiatan belajar, latihan, dan cara mengevaluasi yang dirancang secara sistematis dan menarik untuk mencapai kompetensi yang diharapkan dan dapat digunakan secara mandiri. Untuk itu, diperlukan modul pembelajaran agar peserta didik dapat aktif, kreatif dan dengan mudah berkomunikasi dengan peserta didik lain dengan percaya diri tanpa rasa takut serta tidak merasa bosan ketika proses pembelajaran sedang berlangsung.

Menurut Prastowo (2014:328), interaktif merupakan sifat dimana saling melakukan interaksi antar individu atau saling aktif antar hubungan. Modul elektronik interaktif adalah modul pembelajaran yang berisikan rangkaian kegiatan model pembelajaran yang disusun secara sistematis, operasional dan terarah untuk membantu siswa untuk mencapai tujuan pembelajaran yang dirumuskan secara khusus dalam bentuk elektronik sehingga terjadinya hubungan dua arah antara alat dan pengguna.

Model pembelajaran saat ini sangat banyak modelnya. Untuk mengetahui keberhasilan modul pembelajaran yang digunakan, diperlukan penilaian (evaluasi) model pembelajaran yang baik. Agar proses pembelajaran memberikan hasil optimal dalam meningkatkan aktivitas dan standar ketuntasan belajar dari peserta didik, maka digunakan model pembelajaran CASE (Capture, Solve and Evaluation) yang diharapkan dapat membantu sistem komunikasi antar peserta didik dalam menyelesaikan masalah, sehingga peserta didik dapat percaya diri dengan jawaban yang dia miliki serta dapat bertukar pikiran dengan teman dalam kelompoknya. Model pembelajaran CASE (Capture, Solve and Evaluation) merupakan penggabungan dari model pembelajaran Teams-Games-Tournaments (TGT), Problem Solving, dan Auditory, Intellectually, Repetition (AIR). Dari setiap tipe model pembelajaran tersebut memiliki kelebihan dan kekurangan masing-masing. Oleh karena itu, penggabungan tersebut agar peserta didik dapat berinteraksi antar peserta didik yang akan membuat para peserta didik menjadi lebih efektif dalam proses pembelajaran, sehingga perbedaan kecepatan dan kemampuan tiap-tiap individu peserta didik dapat diperkecil.

Tujuan dalam penelitian ini adalah (1) untuk mendeskripsikan proses pengembangan e-modul interaktif berbasis CASE (Capture, Solve and Evaluation) pada materi luas permukaan dan volume kubus dan balok untuk Sekolah Menengah Pertama Tahun Ajaran 2017/2018, (2) untuk memperoleh hasil pengembangan e-modul interaktif berbasis CASE (Capture, Solve and Evaluation) pada materi luas permukaan dan volume kubus dan balok untuk Sekolah Menengah Pertama Tahun Ajaran 2017/2018, (3) untuk mendeskripsikan hasil uji coba produk yaitu uji coba ahli desain, ahli pembelajaran matematika, pengguna, dan keterlaksanaan pengembangan e-modul interaktif berbasis CASE (Capture, Solve and Evaluation) pada materi luas permukaan dan volume kubus dan balok untuk Sekolah Menengah Pertama Tahun Ajaran 2017/2018. 


\section{METODE}

Dalam mengembangkan e-modul interaktif berbasis CASE (Capture, Solve and Evaluation) digunakan model pengembangan prosedural bersifat deskriptif karena dalam emodul interaktif matematika diperlukan langkah-langkah yang harus diikuti untuk menghasilkan suatu produk. Sebagai acuan dalam pengembangan produk media pembelajaran berbasis multimedia interaktif. Model pengembangan modul interaktif berbasis CASE (Capture, Solve and Evaluation terdiri dari empat tahapan yaitu tahap pendefinisian (define), tahap persiapan (design), tahap pengembangan (develop), dan tahap penyebaran (Dessiminate).

Tahap Pendefinisian (define), dalam tahap ini peneliti akan menganalisa kebutuhan yang diperlukan sebelum merancang e-modul interaktif berbasis CASE (Capture, Solve, and Evaluation). Hal yang perlu diperhatikan dalam tahap ini adalah analisis ujung depan, analisis siswa, analisis tugas, analisis konsep dan perumusan tujuan pembelajaran. Setelah materi, konsep, serta tujuan pembelajaran selesai, maka tahap selanjutnya yaitu tahap perancanagan (design). Pada tahap ini peneliti membuat rancangan media yang akan diuji cobakan. Kegiatan utama pada tahap ini meliputi pembuatan flowchart, storyboard dan penyususnan instrumen. Pada tahap pengembangan (develop) terdiri dari pembuatan e-modul interaktif berbasis CASE (Capture, Solve, and Evaluation) dengan menggunakan program Adobe Flash CS6. Sebagai e-modul interaktif matematika dalam pembelajaran matematika di SMP Negeri 1 Kalibaru pada materi luas permukaan dan volume kubus dan balok akan divalidasi terlebih dahulu oleh ahli media, ahli materi, ahli praktisi dan user. Validator ahli terdiri dari ahli pembelajaran matematika dan ahli desain \& perancang pembelajaran yang melibatkan dosen yang ahli di bidangnya. Validator praktisi melibatkan satu pendidik dari SMP Negeri 1 Kalibaru. Sedangkan validator user melibatkan peserta didik dari SMP Negeri 1 Kalibaru, yaitu 9 peserta didik kelas VIII SMP Negeri 1 Kalibaru.

Uji coba merupakan tolak ukur keberhasilan dalam mengembangkan sebuah produk media. Uji coba dilakukan bertujuan untuk mendapatkan saran maupun tanggapan melalui penilaian terhadap e-modul interaktif berbasis CASE (Capture, Solve, and Evaluation) tersebut, kemudian dilakukan revisi untuk mencapai kelayakan produk yang akan dikembangkan. Sebelum produk yang telah dikembangan diujicobakan, maka produk tersebut divalidasi oleh ahli materi dan ahli media terlebih dahulu. Subjek uji coba dalam penelitian ini adalah siswa SMP Negeri 1 Kalibaru kelas VIII yang dipilih dengan kemampuan yang berbeda-beda sebanyak 9 siswa untuk uji coba terbatas.

Jenis data pada pengembangan ini yaitu jenis data kualitatif dan data kuantitatif. Data kualitatif, didapatkan dari hasil penilaian angket oleh ahli materi, ahli media, ahli praktisi dan user. hasil tersebut dianalisis kembali dengan cara dideskripsikan dan dijadikan sebagai acuan dalam melakukan revisi pada pengembangan-modul interaktif berbasis CASE (Capture, Solve, and Evaluation). Data kuantitatif, didapatkan dari hasil penilaian angket oleh ahli materi, ahli media, ahli praktisi dan user yang kemudian dianalisis dengan teknik presentase.

Instrumen yang digunakan dalam penelitian ini untuk mengumpulkan data yaitu angket. Angket terdiri dari beberapa pertanyan tentang penialain validator pada pengembangan e-modul interakrif matematika. Angket validasi oleh ahli media,ahli materi, ahli praktisi dan user pada e-modul interaktif matematika ini, diperoleh dari pengisian angket dianalisis secara kuantitati fyaitu memberi gambaran dan memaparkan penilaian tentang media pembelajaran berbasis multimedia interaktif sesuai dengan indikator penilaian dengan presentase. Untuk menganalisis data kuantitatif digunakan analisis statistik yang merupakan perhitungan persentase skor angket. Berdasarkan data yang diperoleh dari angket-angket tersebut, maka teknik analisis data terbagi menjadi tiga, yaitu:

1. Analisis Lembar Validasi Instrumen 
Pedoman untuk menginterpretasikan hasil analisis lembar validasi instrumen yaitu dengan menggunakan kriteria penilaian sebagai berikut.

Rumus untuk Lembar Validasi Instrumen adalah $N A=\sum Y$

Keterangan:

$N A \quad=$ Nilai Akhir

$\sum Y \quad=$ Jumlah skor yang diperoleh

Adapun kriteria validitas analisis dari nilai rata-rata pada lembar validasi instrumen diinterprestasikan pada Tabel 3.1 berikut.

Tabel 3.1 Interpretasi Kriteria Hasil Lembar Validasi Angket

\begin{tabular}{lll}
\hline Jumlah Skor & Kriteria & Keterangan \\
\hline $13-22$ & Tidak Valid & $\begin{array}{l}\text { Belum dapat digunakan dan } \\
\text { masih memerlukan konsultasi }\end{array}$ \\
\hline $23-32$ & Kurang Valid & $\begin{array}{l}\text { Dapat digunakan dengan } \\
\text { banyak revisi }\end{array}$ \\
\hline $33-42$ & Valid & $\begin{array}{l}\text { Dapat digunakan dengan sedikit } \\
\text { revisi }\end{array}$ \\
\hline $43-52$ & Sangat Valid & Dapat digunakan tanpa revisi \\
\hline
\end{tabular}

2. Teknik Analisis Angket Kebutuhan Guru dan Kebutuhan Siswa

Analisis data kebutuhan guru dan kebutuhan siswa yang didapat akan diolah dengan menggunakan rumus perhitungan sebagai berikut:

$P=\frac{\sum X}{N} \times 100 \%$ (diadaptasi dari Sugiyono, 2014:137)

Keterangan :

$P \quad$ : Persentase skor

$\sum X \quad$ : Jumlah jawaban tiap opsi dari tiap butir pernyataan

$N \quad$ : Banyaknya subjek uji coba

Berdasarkan hasil perhitungan akan diperoleh presentase tiap opsi jawaban yang kemudian akan disimpulkan.

3. Teknik analisis Angket Validasi Produk untuk Validasi Ahli Media, Validasi Ahli

Materi, Validasi Praktisi dan Validasi User. Nilai yang diberikan oleh validator pada angket validasi produk dianalisis dengan menggunakan rumus-rumus sebagai berikut:

a. Rumus untuk mengolah data per item

$$
\mathrm{S}=\frac{\sum x_{i}}{N} \quad \text { (Sudjana, 2011:109) }
$$

Keterangan:

$\mathrm{S} \quad=$ Rata-rata per aspek

$\sum X_{i}=$ Jumlah seluruh skor per item

$N$ = Banyaknya butir item pernyataan

b. Rumus untuk mengolah data per aspek

$$
\mathrm{K}=\frac{\sum s_{i}}{N}
$$

Keterangan:

$\mathrm{K}=$ Rata-rata total per validator

$\sum s_{i}=$ Jumlah rata-rata seluruh skor per aspek

( $\mathrm{i}=1,2,3, .$. ; aspek isi, aspek tampilan, aspek isi dan tujuan, aspek teknis, atau aspek pembelajaran) 


$$
N=\text { Banyaknya aspek }
$$

c. Rumus untuk mengolah data per validator

$$
\begin{aligned}
& \mathrm{NK}=\frac{\sum K_{\bar{i}}}{N} \\
& \text { Keterangan : } \\
& \mathrm{NK} \quad=\text { Rata-rata total dari semua validator } \\
& \sum K_{i}=\text { Jumlah rata-rata seluruh skor per validator } \\
& (\mathrm{i}=1,2,3 \text {; validator ahli media, validator ahli materi, dan praktisi) } \\
& N=\text { Banyaknya validator }
\end{aligned}
$$

\begin{tabular}{|c|c|c|}
\hline $\begin{array}{l}\text { Persentase NA } \\
(\%)\end{array}$ & Kualifikasi & Keputusan \\
\hline $90 \leq \mathrm{SR} \leq 100$ & $\begin{array}{l}\text { Sangat valid/sangat } \\
\text { praktis }\end{array}$ & $\begin{array}{l}\text { Produk baru siap untuk uji coba di lapangan } \\
\text { /tidak revisi. }\end{array}$ \\
\hline $80 \leq \mathrm{SR}<90$ & Valid/praktis & $\begin{array}{l}\text { Produk baru siap untuk uji coba di } \\
\text { lapangan/tidak revisi. }\end{array}$ \\
\hline $70 \leq \mathrm{SR}<80$ & $\begin{array}{l}\text { Cukup } \\
\text { praktis }\end{array}$ & $\begin{array}{l}\text { Produk dapat diuji cobakan, dengan } \\
\text { menambah sesuatu yang kurang, melakukan } \\
\text { pertimbangan-pertimbangan } \\
\text { penambahan yang dilakukan tidak terlalu } \\
\text { besar dan tidak mendasar. }\end{array}$ \\
\hline $60 \leq \mathrm{SR}<70$ & $\begin{array}{l}\text { Kurang valid/kurang } \\
\text { praktis }\end{array}$ & $\begin{array}{l}\text { Merevisi dengan meneliti kembali secara } \\
\text { seksama dan mencari kelemahan-kelemahan } \\
\text { produk untuk disempurnakan. }\end{array}$ \\
\hline $\mathrm{SR}<60$ & $\begin{array}{l}\text { Tidak } \\
\text { praktis }\end{array}$ & $\begin{array}{l}\text { Produk gagal, merevisi secara besar-besaran } \\
\text { dan mendasar tentang isi media. }\end{array}$ \\
\hline
\end{tabular}

Data persentase penilaian yang diperoleh selanjutnya diubah menjadi data verbal deskriptif dengan menggunakan pedoman kriteria kevalidan pada Tabel 3.2 berikut.

Tabel 3.2 Kriteria Kevalidan

(diadaptasi dari Sudjana, 2014:124)

Jika hasil penilaian validator menunjukkan bahwa e-modul interaktif berbasis CASE (Capture, Solve and Evaluation) yang dihasilkan adalah valid, maka tidak perlu dilakukan revisi. Jika hasil penilaian validator menunjukkan bahwa e-modul interaktif berbasis CASE (Capture, Solve and Evaluation) yang dihasilkan kurang valid, maka perlu dilakukan revisi sebagian.

\begin{tabular}{|c|c|c|c|c|}
\hline Aspek & $\sum x$ & $N$ & $P=\frac{\sum X}{N}(\%)$ & $\begin{array}{c}\text { Kriteria } \\
\text { Kevalidan }\end{array}$ \\
\hline Aspek Materi & 24 & 28 & 85,71 & Valid \\
\hline Aspek Kebahasaan & 20 & 24 & 83,33 & Valid \\
\hline $\begin{array}{l}\text { Aspek } \\
\text { Pembelajaran }\end{array}$ & 14 & 16 & 87,5 & Valid \\
\hline & $\frac{2 P}{n}$ & & 85,51 & Valid \\
\hline
\end{tabular}
Jika hasil penilaian validator menunjukkan bahwa e-modul interaktif berbasis CASE (Capture, Solve and Evaluation) yang dihasilkan tidak valid maka perlu dilakukan revisi total.

\section{HASIL}

Berdasarkan tabel penyajian data, maka pada bagian ini akan diuraikan hasil analisis dari data-data yang sudah diperoleh dan dijelaskan sebagai berikut.

1. Hasil Analisis Data Validasi Ahli Materi.

Berdasarkan analisis hasil validasi ahli materi dapat disimpulkan bahwa emodul interaktif berbasis CASE (Capture, Solve and Evaluation) pada materi luas 
permukaan dan volume kubus dan balok untuk SMP yang dikembangkan memenuhi kriteria kevalidan yaitu valid dengan sedikit revisi dan persentase akhir $85,51 \%$

2. Hasil Analisis Data Validasi Ahli Desain dan Media

\begin{tabular}{lcccc}
\hline \multicolumn{1}{c}{ Aspek } & $\sum \boldsymbol{X}$ & $\boldsymbol{N}$ & $\boldsymbol{P}=\frac{\sum \boldsymbol{X}}{\boldsymbol{N}}(\%)$ & $\begin{array}{c}\text { Kriteria } \\
\text { Kevalidan }\end{array}$ \\
\hline Aspek Isi & 22 & 28 & 78,57 & Valid \\
\hline $\begin{array}{l}\text { Aspek Tampilan } \\
\text { dan Grafis }\end{array}$ & 42 & 48 & 87,50 & Valid \\
\hline \multicolumn{2}{r}{$\boldsymbol{N A}=\frac{\boldsymbol{\Sigma} \boldsymbol{P}}{\boldsymbol{n}}$} & & $\mathbf{8 3 , 0 3}$ & Valid \\
\hline
\end{tabular}

Berdasarkan analisis hasil validasi ahli desain dan media pembelajaran e-modul interaktif matematika yang disajikan dapat disimpulkan bahwa e-modul interaktif berbasis CASE (Capture, Solve and Evaluation) pada materi luas permukaan dan volume kubus dan balok untuk SMP yang dikembangkan memenuhi kriteria kevalidan dengan persentase akhir 84,13\% dengan kategori valid dengan sedikit revisi.

3. Hasil Analisis Data Validasi Praktisi

\begin{tabular}{lcccc}
\hline \multicolumn{1}{c}{ Aspek } & $\sum \boldsymbol{X}$ & $\boldsymbol{N}$ & $\boldsymbol{P}=\frac{\sum \boldsymbol{X}}{\boldsymbol{N}}(\%)$ & $\begin{array}{c}\text { Kriteria } \\
\text { Kevalidan }\end{array}$ \\
\hline Aspek Materi & 26 & 28 & 92,85 & Sangat Valid \\
\hline $\begin{array}{l}\text { Aspek } \\
\text { Pembelajaran }\end{array}$ & 15 & 16 & 93,75 & Sangat Valid \\
\hline Aspek isi & 25 & 28 & 89,29 & Valid \\
\hline $\begin{array}{l}\text { Aspek Tampilan } \\
\text { Grafis }\end{array}$ & 30 & 32 & 93,75 & Sangat Valid \\
\hline & $\boldsymbol{N A}=\frac{\boldsymbol{\Sigma} \boldsymbol{P}}{\boldsymbol{n}}$ & & $\mathbf{9 2 , 4 1}$ & Sangat Valid \\
\hline
\end{tabular}

Berdasarkan analisis hasil validasi praktisi, e-modul interaktif berbasis CASE (Capture, Solve and Evaluation) pada materi luas permukaan dan volume kubus dan balok untuk SMP yang dikembangkan memenuhi kriteria kevalidan dengan kategori sangat valid tanpa revisi dan persentase akhir adalah $92,41 \%$.

4. Hasil Analisis Data Validasi Pengguna/User

\begin{tabular}{|c|c|c|c|c|c|c|c|c|c|c|c|}
\hline \multirow{2}{*}{ Aspek } & \multicolumn{9}{|c|}{ Skor Pengguna/User (\%) } & \multirow{2}{*}{$\begin{array}{l}\text { Rata- } \\
\text { Rata }\end{array}$} & \multirow{2}{*}{$\begin{array}{c}\text { Kriteria } \\
\text { Keprak } \\
\text { tisan }\end{array}$} \\
\hline & 1 & 2 & 3 & 4 & 5 & 6 & 7 & 8 & 9 & & \\
\hline $\begin{array}{l}\text { Aspek } \\
\text { Materi }\end{array}$ & 89,29 & 92,87 & 85,71 & 89,29 & 75 & 89,29 & 92,87 & 82,14 & 89,29 & $87,86 \%$ & Praktis \\
\hline $\begin{array}{l}\text { Aspek } \\
\text { Pembelajar } \\
\text { an }\end{array}$ & 93,75 & 87,5 & 93,75 & 81,25 & 81,25 & 87,5 & 87,5 & 93,75 & 75 & $86,88 \%$ & Praktis \\
\hline $\begin{array}{l}\text { Aspek } \\
\text { Tampilan } \\
\text { Grafis }\end{array}$ & 91,67 & 83,33 & 95,83 & 87,5 & 87,5 & 91,67 & 87,5 & 87,5 & 83,33 & $88,75 \%$ & Praktis \\
\hline
\end{tabular}

Berdasarkan hasil analisis validasi user pada 9 siswa kelas VIII menunjukkan bahwaemodul interaktif berbasis CASE (Capture, Solve and Evaluation) pada materi luas permukaan dan volume kubus dan balok untuk SMP pada materi luas permukaan dan volume kubus dan balok memiliki kriteria praktis dengan sedikit revisi persentase $87,83 \%$ sehingga e-modul interaktif matematika ini dapat digunakan pada skala yang lebih luas. 


\section{PEMBAHASAN}

Dalam pengembangan ini, pengembang menghasilkan bahan ajar e-modul interaktif matematika berbasis CASE(Capture, Solve and Evaluation) pada materi luas permukaan dan volume kubus dan balok untuk sekolah menengah pertama. Pengembangan e-modul interaktif matematika ini dapat mendukung pembelajaran, yaitu dengan menghasilkan produk berupa emodul interaktif matematika yang memberi kesempatan kepada siswa untuk belajar mandiri, meningkatkan motivasi, serta memudahkan siswa untuk memahami materi luas permukaan dan volume kubus dan balok. E-modul interaktif matematika ini disusun dalam bahasa Indonesia, berisi materi luas permukaan dan volume kubus dan balok yang berbasis case (capture, solve and evaluation) pada materi luas permukaan dan volume kubus dan balok untuk SMP, ditampilkan dengan layout yang menarik dalam bentuk e-modul.

Sedangkan pada proses perancangan dan desain e-modul interaktif matematika ini digunakan program aplikasi komputer, yaitu Adobe flash dan Microsoft Word. Selain itu, proses penyusunan e-modul interaktif matematika ini menggunakan tahapan-tahapan model pengembangan 4D (four-D) seperti yang disarankan oleh Thigarajan dkk dalam (Trianto, 2007:65). Model ini terdiri dari 4 tahapan yaitu define (pendefinisian), design (perancangan), develop (pengembangan), dan disseminate (penyebaran).

Sehingga terdapat hasil penilaian e-modul interaktif matematika oleh ahli materi, ahli desain dan media, praktisi/guru matematika, dan user menurut analisis hasil validasi menunjukkan bahwa e-modul interaktif matematika sudah valid dan layak digunakan dalam pembelajaran. Sehingga dapat disimpulkan e-modul interaktif berbasis berbasis case (capture, solve and evaluation) pada materi luas permukaan dan volume kubus dan balok untuk SMP ini layak digunakan sebagai bahan ajar dalam proses pembelajaran matematika khusus siswa kelas VIII SMP/MTs pada materi materi luas permukaan dan volume kubus dan balok yang berbasis case (capture, solve and evaluation).

\section{SIMPULAN DAN SARAN}

Proses pengembangan e-modul matematika ini dilakukan dengan empat tahap dari model 4-D yaitu: (1) Define (Pendefinisian),; (2) Design (Perancangan), meliputi membuat flowchart e-modul, membuat storyboard; (3) Develop (Pengembangan), meliputi pengembangan e-modul interaktif berbasis CASE (Capture, Solve and Evaluation) pada materi luas permukaan dan volume kubus dan balok untuk sekolah menengah pertama tahun ajaran 2017/2018 dan validasi produk oleh beberapa validator yaitu validator ahli materi, validator ahli desain dan validator praktisi. Setelah e-modul matematika dinyatakan valid oleh para ahli dan praktisi, langkah selanjutnya adalah memvalidasikan e-modul kepada user (pengguna) yaitu 9 siswa kelas VIII di SMP Negeri 1 Kalibaru dengan 9 siswa dari kualifikasi tingkat kemampuan yang berbeda ; (4) Disseminate (Penyebaran), meliputi penyebaran produk pada skala yang lebih luas.

Oleh karna itu, berdasarkan pada hasil penilaian validasi produk dalam pengembangan ini yang dilakukan oleh validator ahli materi, validator ahli desain dan validator praktisi, serta user (pengguna), dapat disimpulkan bahwa e-modul interaktif berbasis CASE (Capture, Solve and Evaluation) pada materi luas permukaan dan volume kubus dan balok untuk sekolah menengah pertama tahun ajaran 2017/2018 adalah valid dan layak digunakan.

Penelitian pengembangan e-modul interaktif berbasis CASE (Capture, Solve and Evaluation) hanya dibuat dengan materi luas permukaan dan volume kubus dan balok, selain itu pengembangan ini hanya divalidasi olej kelompok kecil sebanyak 9 siswa, oleh karena itu perlu dilakukan penelitian lebih lanjut terhadap materi pembelajaran matematika. Selain itu bagi pengembang selanjutnya diharapkan melakukan penyebaran e-modul interaktif matematika dalam skala yang lebih luas sekaligus untuk mengetahui keefektifannya, menguji 
keefektifannya dengan metode desain eksperimen research dan untuk tahap penyebarannya di share di blog maupun website agar seluruh dunia mengetahui bahwa dalam variasi bahan ajar, terdapat e-modul interaktif berbasis CASE (Capture, Solve and Evaluation) pada materi luas permukaan dan volume kubus dan balok untuk sekolah menengah pertama tahun ajaran 2017/2018 untuk siswa SMP kelas VIII di Kabupaten Kalibaru.

\section{UCAPAN TERIMA KASIH}

Ucapan terima kasih saya sampaikan kepada rektor Universitas Islam Malang, Dekan FKIP Universitas Islam Malang, Dosen Pembimbing Skripsi, pengelola JPM (Jurnal Pendidikan matematka), dan kedua orang tua, saudara, sahabat, dan teman-teman jurusan pendidikan matematika, serta pihak-pihak yang ikut serta membantu penyusunan artikel ini.

\section{DAFTAR RUJUKAN}

Arsyad, A. (2013). Media Pembelajaran. Jakarta: PT Raja Grafindo Persada.

Darmawan, D. (2014). Pengembangan e-Learning Teori dan Desain. Bandung: PT Remaja Rosdakarya.

Daryanto. (2013). Menyusun Modul bahan ajar untuk persiapan guru dalam mengajar. Yogyakarta: Gava Media.

Hamid, M. S. (2011). Metode Edutainment. Yogyakarta: DivaPress.

Huda, M. (2013). Model-model pengajaran dan pembelajaran. Yogyakarta: Pustaka Belajar. Prastowo, A. (2014). Panduan Kreatif Membuat Bahan Ajar Inovatif. Jogjakarta: Diva Press. Rusman. (2014). Model-Model Pembelajaran: Menggembangkan Profesionalisme Guru. Jakarta: Rajawali Pers.

Setyosari, P. (2015). Metode Penelitian Penddidikan dan Pengembangan. Jakarta: Prenadamedia Group.

Sugiono. (2015). Metode Penelitian Kuantitatif, Kualitatif, dan $R \&$ D . Bandung: Alfabeta.

Trianto. (2007). Model Pembelajaran Terpadu dalam Teori dan Praktek. Surabaya: Pustaka Ilmu.

Undang-Undang Republik Indonesia tentang Sistem Pendidikan Nasional, Surabaya: Media Centre, t.t. 